Tropical Journal of Pharmaceutical Research November 2021; 20 (11): 2425-2431

ISSN: $1596-5996$ (print); 1596-9827 (electronic)

(C) Pharmacotherapy Group, Faculty of Pharmacy, University of Benin, Benin City, 300001 Nigeria.

\title{
Combined administration of nicorandil and atorvastatin in patients with acute myocardial infarction after coronary intervention, and its effect on postoperative cardiac systolic function
}

\author{
Zhirui Sun 1, Yachao Zhang ${ }^{2}$, Yanxiang Shen ${ }^{1 *}$ \\ ${ }^{1}$ The Third Affiliated Hospital of Qiqihaer Medical University Cardiology 4, ${ }^{2}$ Intensive care unit, Qiqihaer Traditional Chinese \\ Medicine Hospital, Qiqihaer, China
}

*For correspondence: Email: quncizhan38718@163.com

Sent for review: 6 June 2021

Revised accepted: 24 October 2021

\begin{abstract}
Purpose: To study the effect of a combination of nicorandil and atorvastatin calcium in patients with acute myocardial infarction after coronary intervention, and its effect on postoperative cardiac systolic function of patients.

Methods: Retrospective analysis was performed on 100 patients with acute myocardial infarction treated with coronary interventional therapy in The Third Affiliated Hospital of Qiqihaer Medical University from April 2019 to August 2020. The patients were randomised into control and study groups, with 50 patients in each group. The control group was treated with nicorandil, while the study group was treated with a combination of nicorandil and atorvastatin. Treatment response, cardiac structural indices, cardiac systolic function, blood lipid profiles, quality of life (QLI) score, Barthel Index (BI), FuglMeyer assessment (FMA), motor function score, incidence of adverse reactions, and blood pressure changes on days 1, 2, 3 and 4 after surgery, were compared between the two groups.

Results: Treatment effectiveness, cardiac systolic function, QLI score, BI index and FMA motor function score in the study group were higher than the corresponding control values $(p<0.05)$. However, lower cardiac structure indices, blood lipid profiles and incidence of adverse reactions were greater in the study group than in the control group ( $p<0.05$ ). No significant disparity in blood pressure was found between the two groups on post-surgery days 1, 2, 3 and 4.

Conclusion: The combination of nicorandil and atorvastatin calcium tablets produced better outcomes in patients with acute myocardial infarction after coronary intervention therapy; furthermore, the combination therapy significantly improved the cardiac systolic function of patients.
\end{abstract}

Keywords: Acute myocardial infarction, Nicorandil, Atorvastatin, Coronary intervention therapy, Cardiac systolic function, Cardiac structure index

This is an Open Access article that uses a funding model which does not charge readers or their institutions for access and distributed under the terms of the Creative Commons Attribution License (http://creativecommons.org/licenses/by/4.0) and the Budapest Open Access Initiative (http://www.budapestopenaccessinitiative.org/read), which permit unrestricted use, distribution, and reproduction in any medium, provided the original work is properly credited.

Tropical Journal of Pharmaceutical Research is indexed by Science Citation Index (SciSearch), Scopus, International Pharmaceutical Abstract, Chemical Abstracts, Embase, Index Copernicus, EBSCO, African Index Medicus, JournalSeek, Journal Citation Reports/Science Edition, Directory of Open Access Journals (DOAJ), African Journal Online, Bioline International, Open-J-Gate and Pharmacy Abstracts

\section{INTRODUCTION}

As a common cardiovascular disease, acute myocardial infarction (AMI) is prevalent in middle-aged and the elderly people. Improvements in standards of living have led to changes in people's eating habits, resulting in increases in the incidence of diseases such as 
hypertension, hyperlipidemia, and diabetes amongst the middle-aged and elderly people [13]. Patients with these diseases are highly susceptible myocardial infarction. Due to a longterm unstable or abnormal high blood pressure, elevated blood glucose, and raised blood lipids, there is reduction in vascular elasticity, as well as impairment of blood circulation, resulting in excessive cardiac load and cardiovascular diseases [4-6].

Percutaneous coronary intervention $(\mathrm{PCl})$ is the most frequently-used treatment strategy for cardiovascular diseases. It is also one of the most effective treatment methods because it clears arterial infarct through interventional therapy, thereby improving blood circulation and alleviating the patient's condition. After $\mathrm{PCl}$, it is necessary to monitor the vital signs and cardiac function of patients to prevent other complications which might affect the prognosis of patients [7-9]. Nicorandil is one of the most popular drugs used in the treatment of AMI. Clinical trials have shown that nicorandil produced a good effect against AMI. Moreover, it is effective against various types of angina pectoris, without producing any obvious adverse reactions. Atorvastatin calcium tablet (ACT) exerts its effects by reducing blood lipid levels and by promoting blood circulation. In this study, the clinical effect of combination of nicorandil and ACT on cardiac systolic function of patients with $\mathrm{AMI}$ after $\mathrm{PCl}$ therapy was investigated.

\section{METHODS}

\section{General information on patients}

We conducted a retrospective analysis of 100 AMI patients who were treated with $\mathrm{PCl}$ in our hospital from April 2019 to August 2020. They were equally randomised into control group and study group. Patients in the study group were aged 59 - 73 years, while those in the control group were aged 56 - 75 years. No significant differences was found with respect to gender, age, medical history, and other general information between the two groups ( $p>0.05)$. Table 1 shows general information on the two groups of patients. The protocol has been approved by the Medical Science Research Ethics Committee of The Third Affiliated Hospital of Qiqihaer Medical University (approval no. 2017-35(102) and followed international guidelines for human studies [10]. All patients enrolled provided a signed informed consent of their own free will.

\section{Inclusion /exclusion criteria}

\section{Inclusion criteria}

The following groups of patients were included in the study: (1) patients whose presentations were consistent with the clinical manifestations of AMI; (2) those who performed PCI in our hospital; (3) patients with no history of drug allergy, history of drug abuse, or no bad habits; and (4) those who had no serious cardio-cerebrovascular disease $(\mathrm{CCVd})$ in the recent past.

\section{Exclusion criteria}

(1) Patients who had mental disorder and could not cooperate in the study; (2) patients who died during first aid; and (3) patients who had congenital heart disease were excluded.

\section{Treatments}

Patients in the control group were treated with nicorandil (NIPRO Pharma Corporation kagamiishi plant; H20160540; 5mg); 1 oral nicorandil tablet three times a day, plus one tablet of aspirin enteric-coated tablets (Bayer Healthcare Co. Ltd; J20171021; 100mg), once a day.

Table 1: Comparison of general patient information between the two groups

\begin{tabular}{lcccc}
\hline Group & Study & Control & $\mathbf{X}^{\mathbf{2}} / \mathbf{t}$ & $\boldsymbol{P}$-value \\
\hline Gender & $26 / 24$ & $27 / 23$ & 0.04 & 0.84 \\
(Male/Female) & $67.34 \pm 3.69$ & $67.61 \pm 3.58$ & 0.37 & 0.71 \\
Age (Year) & $163.02 \pm 10.32$ & $162.61 \pm 10.51$ & 0.20 & 0.84 \\
Hight (cm) & $64.10 \pm 8.84$ & $64.85 \pm 8.22$ & 0.44 & 0.66 \\
Weight (kg) & $5.33 \pm 1.06$ & $5.19 \pm 1.12$ & 0.64 & 0.52 \\
History of heart & $1.30 \pm 0.26$ & $1.35 \pm 0.33$ & 0.84 & 0.40 \\
disease (years) & 19 & 18 & 0.04 & 0.84 \\
Delivery (h) & 15 & 18 & 0.41 & 0.52 \\
Hypertension & 16 & 14 & 0.19 & 0.66 \\
(cases) & & & & \\
Diabetes (cases) & Hyperlipidemia & & & \\
(cases) & & &
\end{tabular}


Patients in the study group were treated with combination of nicorandil tablets and atorvastatin calcium tablets. One tablet of nicorandil was given orally t.i.d.; aspirin enteric-coated tablets (1 tablet q.d.), and atorvastatin calcium tablets (Lepu Pharmaceutical Technology Co. Ltd; H20163270; 20 mg), one tablet, once a day.

\section{Assessment of outcome indices}

Treatment effectiveness, cardiac structure index, cardiac systolic function, blood lipid profiles, QLI score, $\mathrm{Bi}$ index, FMA motor function score, incidence of adverse reactions, and blood pressure changes on days 1, 2, 3 and 4 after operation, were compared between the two groups.

\section{Treatment effectiveness}

During the treatment, if patients showed satisfactory prognosis and recovery of cardiac systolic function, with no adverse reactions, their treatment outcome was classified as significantly effective. The outcome in patients with mild adverse reactions and good cardiac function were markedly effective, while outcome in those with serious adverse reactions, poor prognosis and less obvious cardiac function recovery were ineffective.

\section{Cardiac structure index}

Cardiac structural indicators included aortic valve annulus diameter (AD), left ventricular posterior wall systolic thickness (PWTS), interventricular septal thickness (IVS), left ventricular end systolic diameter (LVIDS) [11-13].

\section{Cardiac systolic function}

Cardiac systolic function covers left ventricular systolic ejection fraction (LVEF) and left ventricle fractional shortening (LVFS) rate.

\section{Blood lipid profile}

Blood lipids included triglycerides, total cholesterol, low-density lipoprotein, and highdensity lipoprotein.

\section{FMA motor function score}

The FMA motor function score (totaling 100 points) is divided into upper and lower limb function tests, with 66 points in upper limb function and 34 points for lower limb function. Higher score indicates better motor function of the patient.

\section{Bi index}

The full score of $\mathrm{BI}$ index is 100 points, which means that the patient can take care of themselves. Scores of 61 - 99 points imply the need for occasional care. In contrast, BI scores between 41 - 60 points indicate need for daily care in most cases; while scores below 40 imply that the patient can hardly live well without help from others.

\section{QLI score}

Quality of life (QLI) score covers daily activities, ability to work, interpersonal relationships, and other parameters as standards. The full score of each standard is 10 points, with higher score suggesting better quality of life of the patients, and vice versa.

\section{Statistical analysis}

Statistical analysis was done using SPSS version 20.0, while GraphPad Prism 7 (GraphPad Software, San Diego, USA) was used for graphics plotting. The counting data and measurement data are expressed as mean \pm standard deviation (SD) and numbers and percentages $[n(\%)]$, and were statistically compared using t-test and $\mathrm{X}^{2}$ test, respectively. Values of $p<0.05$ was claimed as statistically significant.

\section{RESULTS}

\section{Treatment effectiveness}

Table 2 shows that treatment efficiency in the study group was better than that in the control group $(p<0.05)$.

Table 2: Comparison of treatment effectiveness between the two groups

\begin{tabular}{lcccc}
\hline Group & $\begin{array}{c}\text { Markedly } \\
\text { effective }\end{array}$ & Effective & Ineffective & $\begin{array}{c}\text { Total } \\
\text { effectiveness }\end{array}$ \\
\hline Study & 33 & 14 & 3 & $94 \%$ \\
Control & 11 & 16 & 23 & $54 \%$ \\
$X^{2}$ & & & & 20.79 \\
$P$-value & & & & $<0.001$ \\
\hline
\end{tabular}




\section{Cardiac structure indices}

The diameter of $A D$ in the study group was found to be noticeably lower than the control group $(16.21 \pm 1.05 \mathrm{~mm}$ vs $17.15 \pm 1.14 \mathrm{~mm})(t=4.29$, $p<0.001)$; The IVS of the study group (9.37 \pm $0.66 \mathrm{~mm}$ ) was remarkably higher in relative to that of the control group $(11.07 \pm 0.79) \mathrm{mm}$, $(\mathrm{t}=$ $11.68, p<0.001)$; LVIDS of the study group $(40.20 \pm 3.22 \mathrm{~mm})$ was markedly lower than that of the control group $(44.68 \pm 3.39 \mathrm{~mm} ; t=6.78, p$ $<0.001$ ); PWTS in the study group was markedly lower than that in the control group $(9.98 \pm 0.73$ $\mathrm{mm}$ vs $11.95 \pm 0.89 \mathrm{~mm})(t=12.10 ; p<0.001)$. These results are shown in Figure 1.

\section{Cardiac systolic function}

As shown in Figure 2, LVFS of the study group was $34.11 \pm 5.48 \%$, relative to control group value of $30.57 \pm 5.20 \%(t=3.31, p=0.001)$. LVEF of the study group was $52.99 \pm 6.69 \%$, while that of the control group was $47.05 \pm 5.78$ $\%(t=4.75, p<0.001)$. Patients in the study group had markedly higher LVEF and LVFS values than those in the control group $(p<0.05)$.

\section{Blood lipid levels}

There were significantly lower levels of triglycerides, total cholesterol, low-density lipoprotein, and high-density lipoprotein in the study group than in the control group $(p<0.05$; Table 3).

\section{Comparison of QLI, Bi and FMA scores}

FMA motor function score of the study group $(59.21 \pm 3.37)$ was higher than that of the control group (53.84 $\pm 6.39 ; t=4.53, p<0.001)$; QLI score of the study group (87.39 \pm 10.05) was notably higher than that of the control group $(79.22 \pm 8.37 ; t=4.42, p<0.001)$; TBI index score of the study group (68.75 \pm 8.08) was markedly higher than that of the control group $(60.44 \pm 7.22)(t=5.42, p<0.001)$. These results are shown in Figure 3.

\section{Incidence of adverse reactions}

The incidence of adverse reactions in the study group was significantly lower than that in the control group ( $p<0.05$; Table 4$)$.

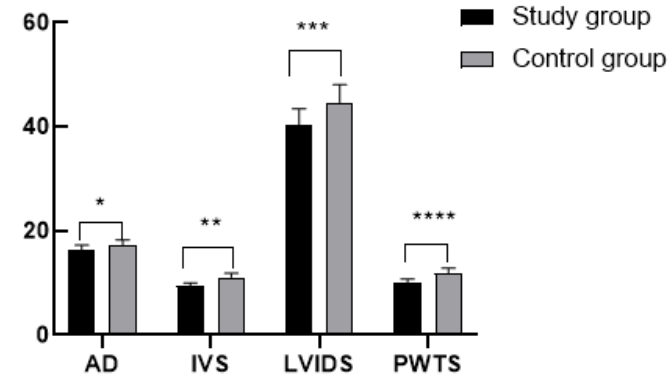

Figure 1: Comparison of cardiac structure indices

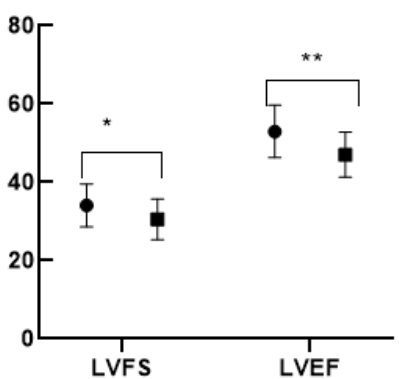

- Study group

- Control group

Figure 2: Comparison of cardiac systolic function between the two groups. * Statistical difference in LVFS between the study group and control group; ** statistical difference in LVEF between the study group and control group

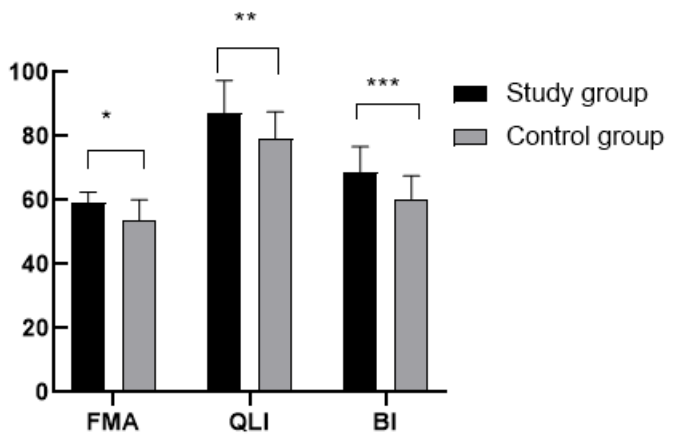

Figure 3: Comparison of $\mathrm{QLI}, \mathrm{Bi}$ index and FMA motor function scores. *Statistical difference in FMA between the study group and control group; ** statistical difference in QLI between the study group and control group; ${ }^{* * *}$ statistical difference in TBI between the study group and control group

Table 3: Comparison of blood lipid levels between the two groups

\begin{tabular}{lcccc}
\hline Group & Total cholesterol & Triglycerides & $\begin{array}{c}\text { Low-density } \\
\text { lipoprotein }\end{array}$ & $\begin{array}{c}\text { High-density } \\
\text { lipoprotein }\end{array}$ \\
\hline Study & $3.51 \pm 0.77$ & $0.92 \pm 0.08$ & $1.61 \pm 0.30$ & $1.09 \pm 0.08$ \\
Control & $5.20 \pm 1.23$ & $1.38 \pm 0.20$ & $2.72 \pm 0.39$ & $1.54 \pm 0.33$ \\
$T$ & 8.23 & 15.10 & 15.95 & 9.37 \\
$P$-value & $<0.001$ & $<0.001$ & $<0.001$ & $<0.001$ \\
\hline
\end{tabular}


Table 4: Comparison of the incidence of adverse reactions

\begin{tabular}{lllll}
\hline Group & Fever & Pneumonia & $\begin{array}{l}\text { Pulmonary } \\
\text { embolism }\end{array}$ & Total incidence \\
\hline Study & 3 & 1 & 0 & $8 \%$ \\
Control & 7 & 3 & 2 & $24 \%$ \\
$X 2$ & & & 4.76 \\
$P$-VALUE & & & 0.03 \\
\hline
\end{tabular}

\section{Blood pressure changes on post-operative days $1,2,3$ and 4}

There were no obvious differences in changes in blood pressure between the two groups on days $1,2,3$, and 4 after operation $(p>0.05)$. These results are presented in Figure 4.

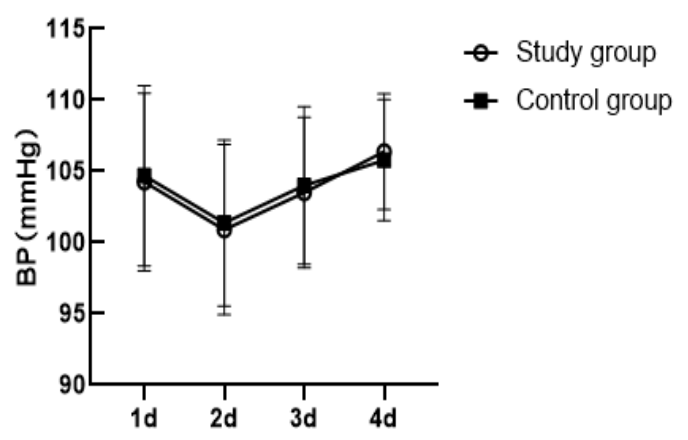

Figure 4: Comparison of blood pressure changes on days 1, 2, 3 and 4 after operation

\section{DISCUSSION}

Nicorandil is one of the major drugs used for the treatment of various types of angina pectoris. It effectively relieves pain and reduces the incidence of cardiovascular disease. Clinical trials have demonstrated that nicorandil effectively enhances the prognosis of patients with cardiovascular disease [14-16]. Atorvastatin calcium tablet is a statin which is used to reduce blood cholesterol levels. Hyperlipidemia patients are usually treated with ACT, since hyperlipidemia tends to cause CCVd. Acute myocardial infarction (AMI) is characterized by sudden onset, rapid advancement and high mortality. Therefore, patients should be sent to hospital for emergency treatment as soon as they show signs of AMI [17-19]. One of the most frequently used methods for the treatment of myocardial infarction is $\mathrm{PCl}$. It lowers the burden on the heart of patients and reduces the possibility of reoccurrence through removal of lesions before intervention so as to reduce pain in patients [20-22].

The therapeutic effect of combination of nicorandil and atorvastatin calcium tablets in patients with $\mathrm{AMI}$ after $\mathrm{PCl}$, and its influence on cardiac systolic function, were determined by comparing treatment effectiveness, cardiac structure index, cardiac systolic function, blood lipid profiles, QLI score, BI index, FMA motor function score, incidence of adverse reactions, and blood pressure changes on postoperative days $1,2,3$, and 4 between the two groups. The findings in this study demonstrated that treatment efficiency, cardiac systolic function, QLI score, Bi index and FMA motor function score of the study group treated with combination of nicorandil combined and atorvastatin calcium tablets were significantly higher in relative to the control group. These results indicate that the combination treatment markedly improved the treatment efficiency, enhanced cardiac systolic function, and raised the quality of life and selfcare ability of patients.

Nicorandil acts on smooth muscle and relieves coronary spasm, thereby relieving angina pectoris. At the same time, it increases coronary blood flow and blood flow velocity, but it has no effect on blood pressure [23]. Therefore, it can improve systolic function of patients. In the study group, heart structure index, blood lipid profiles and the incidence of adverse reactions were observed to be significantly lower as compared with the control group. Atorvastatin reduces blood lipids by stimulating liver LDL receptor. The results obtained in the present study suggest that combination of nicorandil and atorvastatin calcium tablets can considerably reduce the incidence of adverse reactions in patients with AMI after $\mathrm{PCl}$, while enhancing cardiac indicators. There were no marked differences in blood pressure changes between the two groups on days 1, 2, 3, and 4 after operation. It has been reported that blood lipid levels and cardiac function of patients with ST segment elevation acute myocardial infarction were significantly improved after treatment with ACT [24]. This is consistent with the results of the present study, indicating their scientific reliability.

\section{CONCLUSION}

The results obtained in this study indicate that the combination of nicorandil and atorvastatin significantly improves treatment effectiveness in patients with $\mathrm{AMI}$ after $\mathrm{PCl}$, enhances cardiac systolic function, strengthens cardiac systolic 
function, and relieves pain in patients. Therefore, the combination treatment would be of benefit in the management of $\mathrm{AMI}$ after $\mathrm{PCl}$.

\section{DECLARATIONS}

\section{Conflict of Interest}

No conflict of interest associated with this work.

\section{Contribution of Authors}

The authors declare that this work was done by the authors named in this article and all liabilities pertaining to claims relating to the content of this article will be borne by them.

\section{Open Access}

This is an Open Access article that uses a funding model which does not charge readers or their institutions for access and distributed under the terms of the Creative Commons Attribution License (http://creativecommons.org/licenses/by/ 4.0) and the Budapest Open Access Initiative (http://www.budapestopenaccessinitiative.org/rea d), which permit unrestricted use, distribution, and reproduction in any medium, provided the original work is properly credited.

\section{REFERENCES}

1. Lai Q, Yuan G, Shen L, Zhang L, Fu F, Liu Z, Zhang Y, Kou J, Liu S, Yu B, Li F. Oxoeicosanoid receptor inhibition alleviates acute myocardial infarction through activation of BCAT1. Basic Res Cardiol. 2021; 116 (1): 3.

2. Kountouras J, Papaefthymiou A, Doulberis M, Polyzos SA, Zavos C, Kazakos E, Tzika SK, Vardaka E, Liatsos $C$, Katsinelos P. Impact of Helicobacter pylori-related Metabolic Syndrome and Gastroesophageal Reflux Disease on the Risk of Acute Myocardial Infarction. J Neurogastroenterol Motil. 2021; 27 (1): 147-148.

3. Guo L, Zheng J, Zeng H, Zhang Z, Shao G. Atorvastatin potentiates the chemosensitivity of human liver cancer cells to cisplatin via downregulating YAP1. Oncol Lett. 2021; 21(2): 82.

4. Han Z, Wang Y, Li J. Effects of Atorvastatin Combined with Nano-Selenium on Blood Lipids and Oxidative Stress in Atherosclerotic Rats. J Nanosci Nanotechnol. 2021; 21(2): 1331-1337.

5. Stengaard C, Sørensen JT, Rasmussen MB, Bøtker MT, Pedersen CK, Terkelsen CJ. Prehospital diagnosis of patients with acute myocardial infarction. Diagnosis (Berl). 2016; 3 (4): 155-166.

6. Zhang $X$, Wang $S$, Liu J, Wang $Y$, Cai $H$, Wang D, Fang $S, Y u B$. D-dimer and the incidence of heart failure and mortality after acute myocardial infarction. Heart. 2021; 107 (3): 237-244.

7. Tomasik A, Nabrdalik K, Kwiendacz H, Radzik E, Pigoń $K$, Młyńczak T, Sawczyn T, Gumprecht J, NowalanyKozielska E, Lip GYH. Effect of Diabetes Mellitus and Left Ventricular Perfusion on Frequency of Development of Heart Failure and/or All-cause Mortality Late After Acute Myocardial Infarction. Am J Cardiol. 2021; 140: 25-32.

8. Sinn MR, Lund GK, Muellerleile K, Freiwald E, Saeed M, Avanesov M, Lenz A, Starekova J, von Kodolitsch $Y$, Blankenberg S, Adam G, Tahir E. Prognosis of early pre-discharge and late left ventricular dilatation by cardiac magnetic resonance imaging after acute myocardial infarction. Int J Cardiovasc Imaging. 2021; 37 (5):1711-1720.

9. Liu Y, Dai Y, Liu Z, Zhan H, Zhu M, Chen X, Zhang S, Zhang G, Xue L, Duan C, Chen J, Guo L, He P, Tan N. The Safety and Efficacy of Inspiratory Muscle Training for Patients With Acute Myocardial Infarction Undergoing Percutaneous Coronary Intervention: Study Protocol for a Randomized Controlled Trial. Front Cardiovasc Med. 2021; 7: 598054.

10. Department of Health, Education, and Welfare; National Commission for the Protection of Human Subjects of Biomedical and Behavioral Research. The Belmont Report. Ethical principles and guidelines for the protection of human subjects of research. J Am Coll Dent 2014; 81: 4-13.

11. Yandrapalli S, Malik A, Pemmasani G, Aronow W, Shah F, Lanier G, Cooper H, Jain D, Naidu S, Frishman W, Panza J. Sex differences in heart failure hospitalisation risk following acute myocardial infarction. Heart. 2021 Jan 11:heartjnl-2020-318306. 12.Molek P, Zmudzki $P$, Wlodarczyk A, Nessler J, Zalewski J. The shifted balance of arginine metabolites in acute myocardial infarction patients and its clinical relevance. Sci Rep. 2021; 11 (1): 83.

12. Fischer C, Höpner J, Hartwig S, Noutsias M, Mikolajczyk $R$. Participation in disease management programs and major adverse cardiac events in patients after acute myocardial infarction: a longitudinal study based on registry data. BMC Cardiovasc Disord. 2021; 21 (1): 18.

13. Mo F, Luo Y, Yan Y, Li J, Lai S, Wu W. Are activated $B$ cells involved in the process of myocardial fibrosis after acute myocardial infarction? An in vivo experiment. BMC Cardiovasc Disord. 2021; 21 (1): 5.

14. De Rosa S, Spaccarotella C, Basso C, Calabrò MP, Curcio A, Filardi PP, Mancone M, Mercuro G, Muscoli S, Nodari S, Pedrinelli $R$, Sinagra $G$, Indolfi $C$; Società Italiana di Cardiologia and the CCU Academy investigators group. Reduction of hospitalizations for myocardial infarction in Italy in the COVID-19 era. Eur Heart J. 2020; 41 (22): 2083-2088.

15. Datta Chaudhuri R, Banik A, Mandal B, Sarkar S. Cardiac-specific overexpression of HIF-1a during acute myocardial infarction ameliorates cardiomyocyte apoptosis via differential regulation of hypoxia-inducible

Trop J Pharm Res, November 2021; 20(11): 2430 
pro-apoptotic and anti-oxidative genes. Biochem Biophys Res Commun. 2021; 537: 100-108.

16. El Nasasra A, Zeymer U. Current clinical management of acute myocardial infarction complicated by cardiogenic shock. Expert Rev Cardiovasc Ther. 2021; 19 (1): 41 46.

17. Liu Y, Fan Y, Li J, Chen M, Chen A, Yang D, Guan X, Cao Y. Combination of LCZ696 and ACEI further improves heart failure and myocardial fibrosis after acute myocardial infarction in mice. Biomed Pharmacother. 2021; 133: 110824.

18. Jarrah MI, Ababneh MJ, Tawalbeh LI, Hammoudeh AJ, Barukba HM, Othman A. Statin eligibility based on the ACC/AHA guidelines among Middle Eastern patients with diabetes mellitus presenting with acute myocardial infarction. Ann Med Surg (Lond). 2020; 61: 148-154.

19. Hou J, Wang C, Ma D, Chen Y, Jin H, An Y, Jia J, Huang $L$, Zhao $H$. The cardioprotective and anxiolytic effects of Chaihujialonggumuli granule on rats with anxiety after acute myocardial infarction is partly mediated by suppression of CXCR4/NF-KB/GSDMD pathway. Biomed Pharmacother. 2021; 133: 111015.

20. Nowak RM, Jacobsen G, Limkakeng A Jr, Peacock WF, Christenson RH, McCord J, Apple FS, Singer AJ, deFilippi CR. Outpatient versus observation/inpatient management of emergency department patients rapidly ruled-out for acute myocardial infarction: Findings from the HIGH-US study. Am Heart J. 2021; 231: 6-17.

21. Yan L, Wang $H$, Su B, Fan J, Wang $M$, Zhao $X$. Survival after left ventricular free wall rupture following acute myocardial infarction by conservative treatment. Am J Emerg Med. 2021; 39: 21-23.

22. Wang ZD, Li H, Liu M, Li P, Chen J, Liang XW, Zhu XZ, Liao W. Effect of intravenous application of nicorandil on area of myocardial infarction in patients with STEMI during the perioperative stage of $\mathrm{PCl}$. Clin Hemorheol Microcirc. 2021; 77 (4): 411-423

23. $Y u$ J, Zhang L, Zhang $H$. Atorvastatin combined with routine therapy on HIF-1, VEGF concentration and cardiac function in rats with acute myocardial infarction. Exp Ther Med. 2020; 19 (3): 2053-2058. 